\title{
O ESPECTRO DE ABEL / O CÍRCULO INFERNAL DA NECROPOLÍTICA
}

\author{
THE SPECTER OF ABEL / THE INFERNAL CIRCLE OF NECROPOLITICS
}

Victor Galdino Alves de Souza

\section{RESUMO}

O presente texto é um esforço de reunir, em torno do conceito de necropolítica, questões que atravessam a obra de Achille Mbembe e estão ausentes ou são pouco trabalhadas no texto "Necropolítica". O foco será especialmente em distinguir o poder de matar do necropoder, mostrando como este produz uma espacialidade e um espaço onde ele pode circular livremente, destruindo e constituindo realidades e mundos de morte, articulando os elementos que compõem a necropolítica como formação de terror inaugurada na guerra colonial: i) o exercício do poder soberano como poder de matar e transgredir qualquer normatividade para além de si; ii) a normalização do estado de exceção pelo enquadramento de partes do corpo social como inimigas para além das fronteiras da civilização; iii) a militarização do cotidiano e submissão de zonas sitiadas a uma lógica de guerra sem lei. Essa articulação será analisada em termos de sua instrumentalidade e de seu poder de reencenação infinita em variados contextos após o fim da colônia, levando em consideração o papel fundamental da raça na mobilização desses recursos de guerra e morte. Por fim, a ideia é trazer a necropolítica para o centro do dilema ético maior da obra de Mbembe: a demanda pela derrubada violenta da realidade pós-colonial e o risco da circulação infinita da morte na forma do fratricídio.

Palavras-chave: Fratricídio; Emancipação; Imaginação política; Inimizade; Necropolítica; Raça.

\section{ABSTRACT}

This essay is an effort to gather a series of issues around the concept of necropolitics, issues that pervade the work of Achille Mbembe but do not appear in "Necropolitics" or find little room there. It will beespecially focused on the distinction between the mere power to kill and necropower, and the idea is to present this form of power in the fabrication of a spatiality and a space for its free circulation, in the destruction and constitution of realities and death worlds, in the articulation of the several elements of necropolitics as a formation of terror inaugurated in the colonial war: i) exercise of sovereign power as the power to kill and trespass any kind of normativity beyond itself; ii) normalization of the state of exception through the framing of parts of the social body as enemies outside the walls of civilization; iii) militarization of the everyday life and submission of besieged zones to the logics of lawless war. The analysis of this articulation will be focused on its instrumentality and its power of infinite reenactment in different contexts after the colony, and in the role of race as the fundamental resource through which the other resources of war and death are mobilized. At last, the idea is to bring necropolitics to the center of Mbembe's ethical dilemma par excellence: the demand for the violent overthrow of postcolonial reality and the risk of the eternal circulation of death in the form of fratricide.

Keywords: Fratricide; Emancipation; Enmity; Political imagination; Necropolitics; Race.

1 Bacharel, mestre e doutor em Filosofia pela UFRJ. Integrante do Laboratório Filosofias do tempo do agora (Lafita/UFRJ). E-mail: altgaldinovictor@gmail.com. 
Thaumazein, Ano IX, v. 14, n. 27, Santa Maria, p. 95-109, 2021.

São dois filhos bantos, que cantaram sob o sol ao som do berimbau, se matam hoje em Manguinhos, ao troco do capital. (O coice da égua, Valeska Torres)

O poder consiste no ser presente em diferentes mundos, sob diferentes modalidades simultaneamente. [...] é apenas escapando da morte e retornando dos mortos que se adquire a capacidade de se instituir como a outra face do absoluto. Há, portanto, tanto no poder como na vida, uma parte que é como o espectro - uma parte fantasmagórica. (Crítica da razão negra, Achille Mbembe)

O que significa tomar uma palavra - "necropolítica" - como conceito filosófico? Se esse tipo de conceito não é apenas o nome de algo, se deve ser diferenciado de uma palavra em suas funções cotidianas, e se também não pode ser aquilo que o discurso filosófico identifica como produto da abstração de coisas particulares, o que podemos pensar como sua diferença? Se pensamos na ideia de aplicar um conceito, e isso significa percorrer uma série de fenômenos em busca daquilo que pode ser explicado nesse processo de aplicação, parece que não estamos nos distanciando realmente de um conceito como abstração feita a partir de casos e instâncias particulares. Nesse caso, é como se estivéssemos levando adiante um trabalho iniciado por Mbembe, indo atrás de tudo aquilo que ele não identificou explicitamente como necropolítica. Ao mesmo tempo, se assimilamos o conceito em questão, já sabemos o que pode ou não ser capturado por ele - o que não significa que não podemos adquirir ou produzir algo novo, como quando dizemos que um conceito ilumina, de alguma forma, um fenômeno conhecido. Nesses casos, podemos dizer que, agora que aplicamos o conceito com sucesso, o objeto dessa aplicação se mostra diferente. E, claro, esse trabalho pode se estender infinitamente - não faltam exemplos do que Mbembe chamou de "necropolítica" ou "necropoder" ao nosso redor.

Temos ainda a velha questão da representação. Se faz sentido falarmos em identificar um fenômeno como exemplo ou instância de necropolítica, então podemos pensar também no fracasso da aplicação - talvez por uma falha no entendimento do texto, ou por termos nos deixado levar pelo fenômeno errado. O sucesso ou o fracasso aqui dependem do poder representacional do conceito e do estabelecimento de um critério de adequação, e ambas as coisas são encontradas no texto - e apenas no texto, aparentemente. Se Mbembe foi responsável por nos dizer o que é necropolítica, basta interpretarmos o texto corretamente para termos nosso critério. Inicialmente, isso poderia significar que não há revisão possível do conceito motivada pela experiência, mas sabemos que conceitos com o mesmo nome passam por modificações diversas. Ainda assim, para cada versão do conceito, o critério seria sempre e novamente o texto que a apresenta, pois ele nos dirá o que é que teremos de saber, no momento, para 
que nossa aplicação conceitual seja bem-sucedida. De todo modo, o problema da representação parece ganhar sua pertinência apenas enquanto pensamos o conceito de maneira isolada: se recorremos a um texto em que a palavra "necropolítica" está cercada de outras que darão seu sentido, isso não significa, no entanto, a quebra de certo isolamento ou recorte, pois tudo gira em torno da demanda por aplicação que torna o texto apenas o meio pelo qual saberemos como aplicar ou não o conceito em questão. Mas, se deixamos essa demanda de lado ou a tornamos secundária, o que pode nos aparecer?

Em primeiro lugar, temos um convite a uma forma de visualização, uma forma de olhar. Isso aparece logo quando percebemos o vínculo que o conceito de necropolítica carrega com o trabalho de Foucault: sabemos, dessa maneira, que o texto nos chama, mais uma vez, a um modo de olhar o poder que deve separar seu próprio centramento da capacidade que a máquina estatal tem de fazer convergir os variados tipos de exercício de poder. Isso significa, em outras palavras, descentralizar o olhar sem deixar de reconhecer que existe certa tentação, certa força que nos leva à direção oposta, que nos convida à construção abstrata do poder como aquilo que está em outro lugar, concentrado ali, para ser usado contra nós que não estamos de sua posse. Não se trata de um lembrete da angustiante omnipresença das relações de poder - o que precisamos lembrar, antes de qualquer coisa, é que o poder nos atravessa e constitui, e isso implica repensar o que significa nos dobrarmos para participar do mundo que vivemos, deixando também uma dificuldade que surge quando consideramos que somos parcialmente o que essa dobra fez de nós, ainda que ela nos apareça como o ponto privilegiado da nossa rejeição ao poder. Em última instância, trata-se do desafio de lidar com um nó ético que articula nossa rejeição do que vemos negativamente, nosso desejo por uma forma de vida em que isso que rejeitamos não ocorra mais, o fato de que não há subjetividade que não seja atravessada pelo poder, e, consequentemente, a demanda de olharmos o poder de maneira positiva para que possamos trabalhar simultaneamente a rejeição e o desejo. E o poder a ser exercido, tanto agora como resposta, como em uma forma de vida que ainda virá, teoricamente não pode ser o mesmo tipo de poder que o tomado como objeto da crítica - e aqui entramos em outro ponto importante desse legado foucaultiano, pois aquilo que se chamou "ontologia crítica" não tinha como função primária a aplicação do conceito como forma de identificação de diferentes instâncias do mesmo tipo de fenômeno².

A qualificação "crítica" não serve para dizer algo semelhante ao que dizemos com "aplicação", como "colocar a teoria em prática", o que poderia igualmente se prestar a um exercício orientado por fórmulas e receitas, programas epistemológicos que permitiriam a reprodução industrial de ações que, de maneira que nunca se explica claramente, encarnariam a teoria. Se a aplicação do conceito não guarda qualquer mistério significativo, o colocar a teoria em prática permanece como demanda obscura que apenas reencena indefinidamente certo problema envolvendo o vínculo entre mente/alma e corpo - afinal, a questão é precisamente saber como fazer um pensamento ser transmutado em ação corporal. De todo modo, o ponto é romper com a ideia de que nosso problema é o de representar corretamente, que nos basta o saber e o governo dos fenômenos pelo poder dos conceitos. E, deixando de lado todos os problemas que podem ser levantados sobre o que significa, quando lidamos com as funções do discurso filosófico, usar

2 "A ontologia crítica de nós mesmos não deve ser considerada como uma teoria, uma doutrina ou mesmo um corpo permanente de saberes que se acumulam; devemos concebê-la como uma atitude, um éthos, uma vida filosófica na qual a crítica do que somos é [...] a análise histórica dos limites impostos a nós e um teste de seu possível atravessamento" (FOUCAULT, 1994, p. 557, tradução do autor). 
termos como "representação", "correção", "verdade" e "saber", passamos para o que a questão do olhar e da crítica nos apresenta: a possibilidade de lermos o texto filosófico como um lugar onde outras coisas acontecem para além da representação. Por outro lado, podemos dizer que o livro Necropolítica é pouco movimentado nesse sentido - ele não nos oferece muito além de uma constelação teórica que situa o que devemos entender quando assimilamos o conceito de necropolítica e solicita uma reorganização do que normalmente imaginamos ser uma política de morte, especialmente em termos dos desafios que essa política nos coloca. Dito isso, outros livros de Mbembe serão trazidos aqui para explorarmos, dentro dos limites de um texto como este, o que podem ser essa reorganização e esses desafios.

\section{II}

Em primeiro lugar, é preciso lembrar que a política de morte da qual Mbembe fala não se reduz ao extermínio: trata-se da "criação de 'mundos de morte', formas novas e únicas da existência social, nas quais vastas populações são submetidas a condições de vida que lhes conferem o status de "mortos-vivos" (MBEMBE, 2016, p. 146). O exercício do poder soberano de matar e decidir quem deve morrer não é a mesma coisa que o exercício do necropoder, e isso por três motivos: i) não há necropolítica como ato individual (ou mesmo como programa de governo), mas como organização de um cenário no qual esse ato ocorrerá sem maiores consequências, sem uma crise que perturbe, de ponta a ponta, nossa forma de vida; ii) esse cenário não é apenas marcado pela possibilidade do assassinato, mas por uma articulação de fatores como a submissão de parte do corpo social a um estado de sítio e à militarização do cotidiano, a suspensão de direitos e garantias na forma da normalização do estado de exceção, a criação de relações de inimizade que fazem do inimigo algo a ser aniquilado em nome da saúde do corpo social; iii) a morte do assassinato não é a única forma de morte que se manifesta nesse cenário, na experiência vivida desse mundo de morte. No fim, a produção de uma espacialidade e de um espaço - com todas as suas fronteiras, clausuras e compartimentações que não são necessariamente físicas ou geográficas - é a forma de naturalizar a própria existência da necropolítica e do necropoder. Lidamos com algo que, ao mesmo tempo, substitui uma realidade por outra e trabalha para que essa substituição seja esquecida, para que não se manifeste como a violência estrutural intolerável e infernal que é.

Mas, o que significa viver essa realidade nova é uma questão que não é toda trabalhada em Necropolítica. O conceito de necropolítica não existe apenas no texto de mesmo nome, e isso não se deve apenas ao fato das palavras "necropoder" ou "necropolítica" (e variações) aparecerem em outros textos, mas, especialmente, à presença recorrente da ocupação colonial como cenário em que essa organização singular do poder se torna possível, possibilidade que tem como uma de suas condições mais fundamentais a raça. Os problemas que ocupam e assombram Mbembe vêm de um mesmo lugar - onde Mbembe fala sobre raça e colonização, portanto, também está falando em necropolítica, ainda que sem nomear. Vemos, ainda em Necropolítica, dentre outras passagens, a apresentação do necropoder pela imagem da "cidade do colonizado" que encontramos em Condenados da Terra: "[...] um lugar de má fama, povoado por homens de má fama. Lá, nascemos não importa onde, não importa como. Lá, morremos não importa onde, não importa de quê. É um mundo sem intervalos" (FANON, 2002, p. 48, tradução do autor). Esse "não importa" caracteriza a experiência de um lugar produzido pela reestruturação espacial 
que é a colonização, indissociável de uma divisão em dois, sendo "patente que o que divide o mundo é, antes de tudo, o fato de se pertencer ou não a tal ou tal espécie, a tal ou tal raça" (FANON, 2002, p. 48, tradução do autor).

Nessa organização do espaço, encontramos uma semelhança entre as colônias e as fronteiras como lugares de ausência: no espaço apolítico entre um Estado e outro, as colônias são visualizadas e imaginadas como estando fora do lugar das distinções civilizadas que permitiriam, em última instância, civilizar a própria guerra - organizá-la, pelo menos na imaginação política, como um evento dentro da Lei. ${ }^{3}$ E é assim que "[t]odas as manifestações de guerra e hostilidade marginalizadas pelo imaginário legal europeu encontraram lugar para reemergir nas colônias" (MBEMBE, 2016, p. 134). Aqui, podemos falar em duas coisas: um recalcamento que se desfaz na invasão de um território que, na organização colonial da visibilidade, abre-se à experiência como lugar em que "o europeu, liberto não apenas de todas as inibições, mas de qualquer necessidade de vigiar sua imaginação, pode revelar seu 'outro' eu" (MBEMBE, 2001, p. 185, tradução do autor); no exercício de criatividade que, não se contentando com a possibilidade de entregar ao mundo um terror que estava interditado em solo europeu, engaja-se na invenção de novas possibilidades de violência. Além disso, na colônia, o inimigo é construído por exteriorização: o "selvagem" que não age de acordo com as distinções é o próprio europeu na colônia, europeu que não é o que imaginava ser na Europa, europeu retirado de si, tornado imagem indesejável, sua sombra, a noite, negro. Podemos dizer: para que se veja o que não está no outro, para que o outro se torne Outro, é preciso doar algo de si. O "selvagem" na colônia, afinal, é de autoria europeia e sua imagem não se produziu ex nihilo, mas na loucura da guerra. Faz-se, dessa maneira, a encarnação da imagem da noite através do material presente nos cantos escuros da alma europeia.

Se a necropolítica emerge na recusa de integrar ao imaginário legal europeu o lugar que será construído como colônia, é no que essa negação possibilita e nas condições de possibilidade dessa negação que encontraremos aquilo que, caso não desapareça e seja novamente interditado em todo e qualquer imaginário social, continuará a servir para o eterno retorno dos mundos de morte. E, no centro desse empreendimento que liberta o desejo de toda restrição, está a raça: "uma das matérias-primas com as quais se fabrica a diferença e o excedente, isto é, uma vida que pode ser desperdiçada ou dispendida sem reservas" (MBEMBE, 2018, p. 73). Na colônia, o poder soberano pode aparecer como um poder de não-ver que faz surgir dois vazios: para todos os efeitos, a realidade vivida pelo colonizador é uma em que "a terra é considerada pertencente à categoria de coisas que nunca pertenceram a ninguém (MBEMBE, 2001, p. 183, tradução do autor), um território livre para apropriação por estar vazio de sujeitos portadores de direito sobre o mesmo, vazio que só é percebido porque o poder soberano se tornará "[...] poder de ver ou de não ver, de ser indiferente, de tornar invisível o que não se faz questão de ver" (MBEMBE, 2018, p. 199). Ou seja, ninguém ocupa a terra porque o que se encontra nela é efetivamente

\footnotetext{
3 "No mesmo contexto, as colônias são semelhantes às fronteiras. Elas são habitadas por "selvagens". As colônias não são organizadas de forma estatal e não criaram um mundo humano. Seus exércitos não formam uma entidade distinta, e suas guerras não são guerras entre exércitos regulares. Não implicam a mobilização de sujeitos soberanos (cidadãos) que se respeitam mutuamente, mesmo que inimigos. Não estabelecem distinção entre combatentes e não combatentes ou, novamente, "inimigo" e "criminoso". Assim, é impossível firmar a paz com eles. Em suma, as colônias são zonas em que guerra e desordem, figuras internas e externas da política, ficam lado a lado ou se alternam" (MBEMBE, 2016, p. 133).
} 
ninguém. Da perspectiva do colonizador, essa conjunção de vazios autoriza o excesso e a transgressão: as pessoas que habitam aquelas terras são como recursos minerais, vegetais e animais, construídos enquanto fenômeno econômico para além de qualquer jurisdição - no limite, para além de qualquer cálculo, ainda que o esgotamento total desses "recursos" seja indefinidamente adiado ou mesmo impedido 4 . Em outras palavras, fazer o humano aparecer como recurso pelo desaparecimento de sua humanidade, no contexto de uma economia governada pelo estranho desejo de conciliar acúmulo e consumo, não se diferencia da construção desse não-mais-humano como algo que sobra em uma terra de abundância.

Através de uma cegueira radical, o colonizador pode enxergar o caminho aberto para a manufatura de uma nova realidade mais apropriada aos seus desejos e às suas fantasias - como parte do que podemos chamar de "partilha colonial do sensível"s, essa cegueira sobreviveu ao fim da colônia como forma de organizar a visibilidade e a invisibilidade sociais, forma que se torna independente das demandas de seu lugar de fabricação, especialmente por guardar o poder de remontar o cenário de sua presentificação e desdobramento em outras terras. Se podemos falar que nada do que se deu através dessa cegueira se tratou de um engano colossal, um problema generalizado de representação incorreta do real, e se podemos falar que a colonização foi a produção efetiva de uma realidade nova, isso significa que essa realidade foi, antes de qualquer coisa, uma encarnação violenta das mais variadas fantasias: "Eu tento ler a brutalidade colonial e pós-colonial como obra que requer virtuosidade, criatividade da imaginação, extravagância nos gastos, manufatura de prodígios e de superstições", diz Mbembe (2006, p. 184, tradução do autor). Herdamos as ruínas de um mundo de fantasia tornado realidade, com seu "poço inesgotável de fantasias" (MBEMBE, 2018, p. 131), expressão de uma forma de racionalidade que nunca se opôs radicalmente à loucura senão enquanto gesto retórico vazio ou tentativa de mascaramento.

A permanência da raça enquanto instrumento de dominação e arma de guerra nos dias de hoje deveria bastar para nos perguntarmos se faz mesmo sentido considerá-la como fabricação pura ou meramente irracional, fantasiosa, delirante - ou se é mais racional tomá-la como mistura onde as variadas potências do sujeito contribuem de alguma forma ou outra. Afinal, todo o problema do não-ver começa com um não querer ver, recusa que articula desejo e percepção nas racionalizações que serão elaboradas como justificativa para a cegueira. O trabalho da fantasia não é solitário, e nem a racionalidade opera na clausura de uma autonomia imaginada: temos uma colaboração aqui, esforço integrado, longe

4 Podemos considerar que a aniquilação definitiva e total não pode se dar sem que a própria biopolítica desapareça como a conhecemos. De fato, pensando com Mbembe e em termos foucaultianos, a necropolítica não é apenas o lado sombrio das políticas de preservação e defesa da vida, mas seu complemento necessário, sem o qual sequer faria sentido haver vida. Em Afropessimism de Frank Wilderson, encontramos uma variação dessa forma de pensar que apresenta "a violência antinegra" como uma espécie de prática terapêutica que permitiria a regeneração constante da "raça humana" - além disso, o genocídio completo das pessoas negras levaria a humanidade a "perder sua coerência conceitual", a "um abismo epistemológico. O Negro é necessário para marcar a fronteira da subjetividade humana” (2020, p. 164, tradução do autor).

5 "O animal falante, diz Aristóteles, é um animal político. Mas o escravo, se compreende a linguagem, não a 'possui'. Os artesãos, diz Platão, não podem participar das coisas comuns porque eles não têm tempo para se dedicar a outra coisa que não seja o seu trabalho. Eles não podem estar em outro lugar porque o trabalho não espera. A partilha do sensível faz ver quem pode tomar parte no comum em função daquilo que faz, do tempo e do espaço em que essa atividade se exerce. Assim, ter esta ou aquela 'ocupação' define competências ou incompetências para o comum. Define o fato de ser ou não visível num espaço comum, dotado de uma palavra comum etc. Existe portanto, na base da política, uma 'estética'” (RANCIÈRE, 2009, p. 16). 
de ser plenamente deliberado, estratégia improvisada de guerra que convocará todas as capacidades psíquicas em nome da conquista territorial, da expansão planetária da exploração, do progresso social e científico. Assim, os "mundos de morte" produzidos pela necropolítica de nossos dias são como reencenações cuja possibilidade está inscrita na própria organização social da sensibilidade e da imaginação. A colônia é um modelo: não por ter sido elaborada enquanto tal, mas, por reunir, pela primeira vez, em escala planetária, os elementos que, quando reunidos, farão aparecer o que Mbembe nomeia "necropolítica”. É um modelo no sentido da possibilidade de sua reencenação ilimitada, e também no da produção de uma forma de experimentar o tempo.

E que forma é essa? É aquela que nos permite dizer algo como "toda a performance do racismo cotidiano pode ser vista como a reatualização da história", ou ainda: "A ferida do presente ainda é a ferida do passado, e vice-versa, o passado e o presente se entrelaçam como resultado" (KILOMBA, 2019, p. 158). Assim, temos "os 'tempos de outrora' e o 'lá longe' como constitutivos daquilo que está acontecendo aqui e agora e daquilo que está para acontecer" (FERREIRA DA SILVA, 2018, p. 408). No entrelaçamento de tempos distintos, algo que tem um começo se retira da linearidade temporal e histórica, assume certa atemporalidade, organiza a experiencia da reencenação em termos de simultaneidade (a convivência e dependência entre terror e biopolítica), permanência (a continuidade do terror para além de um passado sombrio, imaginado como objeto de uma superação progressista), expansão (a independência do terror e de suas tecnologias, sua adaptabilidade e seu caráter instrumental). Essas modalidades do terror produzem uma experiência própria da temporalidade, o "tempo do emaranhamento" (MBEMBE, 2011, p. 16), onde a flecha dá lugar ao novelo, o sujeito é afetado de todas as direções, movimentando-se temporalmente de maneira flutuante, instável, beirando o caos. No fim, a experiência do necropoder envolve sempre, de alguma maneira, uma assombração, ferida que remete ao tempo da colônia, que nos lembra que a superação inscrita no tempo histórico da linearidade progressista é apenas uma forma de organizar o olhar, forma que se desintegra diante da percepção da face sombria de nossa forma de vida. Assim, "necropolítica" é o nome daquilo que nunca foi embora, daquilo que sempre esteve na pós-colônia, do que é continuamente naturalizado para que não haja futuro sem sua presença - é aquilo que é experimentado como o que nunca deixou, deixa ou deixará de acontecer, enclausuramento do próprio tempo.

\section{III}

Se perguntamos sobre o que vem depois da cena inaugural, sobre o destino da realidade colonial na pós-colônia, encontramos, como diferença fundamental, uma nova indiferenciação. O fim da colônia foi o desaparecimento da linha infernal que separava um Fora e um Dentro, deixando evidente - para quem se engajasse na produção dessa evidência, como fazia Fanon, por exemplo - que havia uma estrangeiridade na violência: ela vinha de outro continente, de lá recebia seu sentido e sua ordem, ainda que, soberana na colônia, a autoridade local pudesse exercê-la com certa liberdade. Por outro lado, a violência estrangeira levava à insurreição violenta e à instrumentalização da violência como necessidade anticolonial. A delimitação dos alvos era amplamente auxiliada - e mesmo tornada possível - pela condição estrangeira daqueles que exerciam o necropoder. No entanto, os processos de independência dissolveram a distinção entre metrópole e colônia. A necropolítica se torna igualmente independente. 
Agora, pode ser reencenada, revisada e atualizada de maneira autônoma, nacional e nacionalista - pode ser até mesmo democratizada. Como dito, há uma instrumentalidade a ser considerada: a construção da inimizade como relação de hostilidade absoluta é um recurso, por exemplo. Com ela, temos a possibilidade da exceção como norma para uma parte, desde que alguma outra parte conheça a exceção apenas enquanto tal - outro recurso, outro exemplo. As coisas estão simplesmente aí para serem usadas.

"Estão simplesmente aí" - o que significa isso? Onde for conjurada a articulação entre militarização do cotidiano, estado de exceção e o poder soberano de transgressão e doação de morte, onde essa articulação produzir um inimigo com o qual não será possível estabelecer laços "de civilização", haverá necropolítica. O trabalho conceitual em cima dessa articulação serve para nos levar, dentre outras coisas, a olhar o nosso objeto por dentro, em sua dimensão funcional e estrutural, e em seu poder de presentificação em contextos que, a princípio, são radicalmente distintos uns dos outros - em certo sentido, isso significa que recebemos um convite a olhar semelhança e diferença de outra maneira, desviando nossa atenção das manifestações mais gritantes do poder e do necropoder. Ou seja, contornar o regime de visibilidade que nos é dado, inclusive no interior do progressismo, para que certas coisas deixem de aparecer e outras passem a aparecer em seu lugar. Além disso, temos o problema do que ainda não ocorreu e espreita sempre no horizonte como ameaça: quais são as manifestações da necropolítica que ainda podem surgir? Se muitas das diferenças que experimentamos entre governos dizem respeito aos diferentes modos como a mesma política se dá e o mesmo poder é exercido, o que pode nos reservar o futuro do Estado se, de nenhuma das partes que o reivindicam, há qualquer compromisso em desfazer a necropolítica? As ferramentas para a manufatura e reprodução de mundos de morte permanecem aí - mal se percebe a presença delas enquanto ferramentas quando se olha diretamente para o corpo solar da democracia.

Pensar nessa instrumentalidade nos remete ao destino da raça e do que foi feito dela em termos de organização violenta da vida. O que ainda se faz com essa construção imaginária que, encarnada na realidade ao ponto de ocupar o seu lugar, foi o recurso fundamental para que o colonizador se percebesse e sentisse autorizado a extrapolar os limites que sua própria civilização definia? Como parte de uma constelação, a raça sempre esteve vinculada a outras imagens que podiam ser lançadas em direção a outras pessoas. Por falta de termos mais apropriados, podemos falar na diferença entre perceber um sujeito como negro e perceber um negro ou uma negra. Igualmente, podemos dizer que há algo no racismo que possibilita o intercâmbio entre essas duas maneiras de perceber, de modo que, ainda no tempo da colônia, algumas representações serviam para criar esse como negro do sujeito não-racializado. Dentro da própria metrópole britânica, por exemplo, a imagem da degeneração era usada como ferramenta de rebaixamento hierárquico não apenas de irlandeses, como de "outros 'negros brancos': judeus, prostitutas, a classe trabalhadora, trabalhadores domésticos, e assim por diante" (MCCLINTOCK, 2010, p. 93). Dessa forma, "o homem inglês de classe média era posto no pináculo da hierarquia da evolução" (MCCLINTOCK, 2010, p. 96), e o resto das classes sociais apareceria, ao longo da linha do progresso, classificado e distribuído de acordo com suas semelhanças e diferenças em relação aos extremos. O que está em jogo é o poder de aproximar e distanciar uma pessoa do continente africano, lugar de atraso, ou mesmo fora da História, visualizado como "espaço anacrônico" onde encontramos seres anacrônicos por caracterizados por sua "regressão temporal" (MCCLINTOCK, 2010, p. 186). Essa proximidade se dá 
ao longo de um espaço linearizado e organizado pela imagem do progresso, de modo que pessoas são percebidas como se fossem negra por sua posição atrasada na linha imaginada.

Há outras possibilidades: a ideia de um devir negro do mundo, por exemplo, parece apontar para outra coisa. Não se trata, nesse caso, de produzir uma medida precisa e explícita para alocar diferentes grupos em uma hierarquia, mas de investir o suficiente em um como se para despertar a maquinaria necropolítica para novos alvos. Esse investimento nos aparece mais explicitamente nas variadas construções de um inimigo que, ainda que enquadrem grupos não-racializados ou pessoas não-negras, vão recuperar elementos da sensibilidade e do imaginário que constituíram o cenário da guerra colonial. Em outras palavras, tudo aquilo que permite reorganizar a subjetividade para que seja indiferente ou mesmo tenha prazer com a tortura, o encarceramento em massa, o assassinato extrajudicial, a restrição da mobilidade, dentre outras coisas. Trata-se de construir lugares em que "o crime constitui parte fundamental da revelação, e a morte de [...] inimigos é, em princípio, desprovida de qualquer simbolismo" (MBEMBE, 2020, p. 69) - lugares não necessariamente ocupados por pessoas negras, ainda que, em muitos casos, eles existam porque foram, desde o início, produzidos para essa ocupação.

Assim, nas duas possibilidades de aproximação e expansão, o que vemos é a movimentação de imagens que, inicialmente fabricadas para formar uma constelação imaginária colonial, passam a circular para além dessa cena inaugural, como ferramentas disponíveis - seja para disciplinar, seja para construir mundos de morte. Se a raça foi empregada, por exemplo, para a produção da imagem do excedente, que permitiria o aparecimento de certas vidas como aquilo que está sobrando e pode ser livremente desperdiçado, sem peso na consciência, sem prejuízos para a economia, isso não significou a indissociabilidade dessas imagens. O racismo é tornando independente enquanto "economia sacrificial cujo funcionamento exige, de um lado, a redução generalizada do preço da vida e, de outro, a familiarização com a perda" (MBEMBE, 2020, p. 69). Da mesma forma, também se tornou independente o imperativo civilizatório que lançou guerra no continente africano contra "selvagens" que eram imaginados como estando além de qualquer pacto ou contrato Para isso, nomeia-se de outras formas a parte enquadrada como "selvagem" terroristas, bandidos, vagabundos. Suspeitos. E, ocasionalmente, no disparo de ódio que revela, sem qualquer dúvida, a permanência do passado no presente: selvagens novamente.

Dito isso, o que o conceito de necropolítica nos instiga a olhar quando falamos nas relações de inimizade contemporâneas é: onde foram parar o Fora e o Dentro? É de dentro de nossas sociedades que emergem as autoridades, as milícias, as empresas de segurança etc. Um irmão vai para o tráfico, outro entra para a polícia. Um governa, outro tenta derrubar o governo pela força de um golpe armado. "Hoje vítima, amanhã carrasco, e depois vítima novamente - o ciclo do ódio não para de se enovelar e de espaIhar seus nós por toda parte" (MBEMBE, 2020, p. 70). Por todos os lados, antigos recursos são recuperados, com algumas variações - tecnologias de morte são herdadas e partilhadas na pós-colônia, ainda que de maneira desigual, por pessoas que, em última instância, não podem ser identificadas rigorosamente como se identificava militares e autoridades agindo em nome da metrópole - não há mais colônia e metrópole, mas uma espécie de dissolução e reorganização de ambas no mesmo território. Nesse processo, herdam-se não apenas as tecnologias e seus usos, mas a promessa do acúmulo ilimitado que anima a fé na morte do outro como condição para a própria vida - promessa que Mbembe chama o "pequeno segredo' da colônia e que explica a potência imaterial do potentado colonial” (MBEMBE, 2018, p. 205). 
Legado que alimenta, ainda hoje, a antiga fantasia soberana da desinibição absoluta: "A pedra de toque do dispositivo fantasmático do potentado é a ideia de que não há nenhum limite para a riqueza nem para a propriedade, e, portanto, nem para o desejo" (MBEMBE, 2018, p. 205).

Aquilo que o colonizador efetivamente fez na colônia se mostrou como possível, como desejável - o encontro colonial, diz Mbembe, "[c]olocou desejos em movimento que colonizador e colonizado tiveram de esconder de si ocasionalmente, e que, justamente por isso, foram reprimidos no inconsciente" (2007, p. 54, tradução do autor). A colonização foi um processo massivo de enfeitiçamento. Deixando-se levar pela possibilidade de exercer também a liberdade destrutiva do colonizador, "o colonizado entra em outro ser e passa a viver, a partir desse momento, sua obra, sua linguagem, assim como outros processos sedutores" (MBEMBE, 2007, p. 54, tradução do autor). Essa liberdade, claro, só pode ser exercida no enclausuramento do outro - não há espaço possível para sua manifestação igualitária. Mas, dessa vez, quem a encarna enquanto seu sujeito por excelência? Há apenas irmão contra irmão. A autoridade e a luta contra a autoridade reúnem, em certo sentido, o mesmo tipo de sujeito - o que é especialmente nítido quando lembramos que, nas muitas sociedades africanas produzidas na colonização, são africanos negros que ocupam o governo, inclusive assumindo a figura do autocrata, encarnando o desejo pela sacralização de si como fetiche e aspirando uma autoridade divina. ${ }^{6}$

Em Sair da grande noite, por exemplo, Mbembe reconta o destino de muitas das pessoas que entregaram suas vidas à luta pela independência do que veio a se chamar "República dos Camarões", sua terra natal: "Os dirigentes nacionalistas que haviam entrado na clandestinidade foram executados. Seus restos mortais foram profanados e eles foram enterrados rapidamente, como se fossem bandidos de estradas" (MBEMBE, 2019, p. 39). A enquadramento da luta armada como terrorismo permitiria, como os anteriores que sustentaram a inimizade como demanda de aniquilação e relação extralegal, o estabelecimento de um "estado de emergência permanente" (MBEMBE, 2019, p. 40) e um programa de apagamento generalizado da memória anticolonial. "Ao fazer isso, o novo Estado independente supunha escapar da pergunta outrora feita a Caim: 'Onde está seu irmão Abel?'” (MBEMBE, 2019, p. 40). A maquinaria de controle e extermínio deixada pela colonização se volta contra quem tentou derrubá-la, e "independência" passa, no fim das contas, a significar: "não se pode descolonizar tudo de uma vez" (MBEMBE, 2019, p. 45). Nesse movimento, surge o problema do fratricídio na dissolução do colonizador na colônia, da colônia na sociedade independente: "na cabeceira do Estado independente jazia o crânio de um parente morto" (MBEMBE, 2019, p. 40)7.

6 Cito aqui Sobre a pós-colônia (MBEMBE, 2001, p. 111, tradução do autor): "Dentre outras coisas, um fetiche é um objeto que aspira à sacralização, que reivindica o poder e que busca manter uma relação próxima e íntima com quem o porta. O fetiche também pode assumir a forma de um talismã que invocamos, reverenciamos ou tememos. Na pós-colônia, o poder do fetiche não está apenas investido na figura do autocrata, mas em todas as figuras da ordem e seus agentes (partido único, polícia, soldados, subprefeitos, comissários, intermediários e outros traficantes...).

7 Como dito em Políticas da inimizade (MBEMBE, 2020, p. 63-4): "Em muitas regiões do mundo pós-colonial, o ponto de virada que representou a generalização da relação belicosa foi muitas vezes a consequência derradeira do curso autoritário seguido por muitos regimes políticos confrontados a intensos protestos. Na África, em particular, o terror assumiu muitas formas O primeiro foi o terror estatal, particularmente quando se tratava de conter a deriva contestatória, se necessário por meio de uma repressão ora sorrateira, ora expedita, brutal e desmedida [...] Em alguns casos, regiões inteiras foram colocadas sob dupla administração civil e militar. Onde os regimes estabelecidos se sentiam mais ameaçados, levaram a lógica da radicalização à sua conclusão lógica, instigando ou apoiando o surgimento de quadrilhas ou milícias controladas 
Caim mata Abel, mas como fazer justiça ao espectro de Abel? Como sustentar uma autonomia e uma soberania sem manter girando a roda que movimenta o fratricídio? A morte de Abel só pode ser vingada pela morte de outro Abel? Essas questões são especialmente relevantes quando pensamos na política da vida e na construção de uma nova humanidade que, na esteira de Fanon, ainda são pensadas como reorganização terapêutica do poder pela violência: o "longo caminho de cura" proposto por Fanon "operava por meio de um colossal trabalho sobre si mesmo, por meio de novas experiências do corpo, do movimento, do estar junto [...] e eventualmente por meio do exercício da violência” (MBEMBE, 2020, p. 17). No entanto, essa instrumentalização da violência guardava e ainda guarda, impassível de exorcismo, a possibilidade da imitação da violência que convocou o sujeito revolucionário em primeiro lugar: "Bloqueada numa repetição estéril, ela podia a todo momento se degenerar e ver sua energia colocada a serviço da destruição pela mera destruição" (MBEMBE, 2020, p. 18). Como ferramenta de reabilitação do poder criativo que faria surgir uma nova humanidade, a "violência regenerativa da descolonização" tinha "uma dimensão incalculável e, devido a essa incalculabilidade, era essencialmente imprevisível. Uma vez desencadeada, podia se tornar incontrolável (MBEMBE, 2020, p. 129). É dessa ambiguidade fundamental da violência no contexto da guerra colonial que viria seu duplo poder de veneno e remédio: "era ao mesmo tempo algo capaz de salvar e também a fresta por onde o perigo invadia a casa” (MBEMBE, 2020, p. 129).

Apontar para essa duplicidade aparentemente incontornável não significa uma rejeição da violência, mas uma demanda pela reorganização de nosso imaginário político - especialmente no sentido de não deixarmos de nos assombrar, ainda no presente, pelo destino da violência como problema ético e político, pelo espectro de Abel. Assim, o desafio maior que a permanência da necropolítica apresenta é o de como resolver o problema da descolonização que não veio, da autonomia que foi devorada pelo espírito da violência entranhado na própria terra, no tempo em que o terror apenas se multiplica e reinventa. Em última instância, trata-se do desafio de construir um futuro radicalmente oposto à realidade produzida pelo necropoder. Se é preciso fazer guerra contra a própria realidade, substituí-la por outra - não no sentido de retornar a uma configuração anterior e inocente das coisas -, ainda lidamos com a mesma dúvida sobre a violência que, em outro tempo, retornava ao colonizador pelas práticas anticoloniais. Se ela está a serviço da emancipação, "há uma questão sobre a violência poder permanecer como puro instrumento ou se ela virá a definir, assombrar e atormentar a política que se instala por meios violentos" (BUTLER, 2015, p. 191, tradução do autor). Onde a recusa de certa realidade se desdobrou na construção de comunidades alheias ao poder estatal, ainda que não inteiramente livres dele enquanto ameaça externa, a questão foi abandonada. No entanto, onde há demanda por uma derrubada violenta da ordem, essa questão ainda não foi resolvida.

Um dos lados dessa questão aparece em Necropolítica como o problema da distinção "entre autênticas expressões da soberania e a as ações do inimigo", "entre o 'erro' do cidadão e o 'crime' do contrarrevolucionário na esfera política" (MBEMBE, 2016, p. 130). A fé na capacidade de realizar essa distinção pelo domínio da razão se mostra a "tentativa errante de criar um espaço em que o 'erro' seria reduzido, a verdade, reforçada, e o inimigo, eliminado" (MBEMBE, 2016, p. 130). No entanto, o que a experiência histórica nos mostra é a ausência de um controle sobre as fronteiras entre aliado e inimigo que

fosse por acólitos e outros despachantes da violência operando nas sombras, fosse por lideranças militares ou políticas ocupando posições de poder dentro das estruturas formais do Estado". 
não fosse parcialmente arbitrário, e que não acabasse na reivindicação permanente da soberania como poder de morte. "Na visão de Fanon, não se tratava tanto de conquistar o Estado, mas de engendrar uma outra forma de soberania" (MBEMBE, 2020, p. 129), e a fé no poder e na autonomia da razão aumentaria as chances de a soberania desejada acabar aparecendo como a que se tomou como indesejável no início, de modo que essa circularidade é percebida como progresso. Partilhar dessa fé significaria, em última instância, que não serei o próximo na guilhotina, que estarei sempre do lado certo da história. O problema que se apresenta, então, é o de fazer a relação de inimizade perder seu sentido, sua desejabilidade intrínseca enquanto ferramenta - desde o início ou em algum momento. É esse caráter intrínseco que parece nos lançar de volta à conversão teoricamente ilimitada do erro em crime, ao abandono das práticas revolucionárias diante da possibilidade de participação na soberania que, aparecendo primeiramente como realidade indesejável, agora retorna como promessa sedutora. A questão não é, para Mbembe, o que as pessoas vivendo cotidianamente o terror decidem usar para se libertar das variadas formas de clausura e morte em vida, mas desfazer um cenário, um lugar, sem que ele nos devore no processo.

Retornando ao pequeno segredo da colônia, é preciso lembrar, mais uma vez, que é na "partilha dos mesmos fantasmas" (MBEMBE, 2001, p. 231, tradução do autor) que encontramos a derradeira vitória do empreendimento colonial: não apenas dominar, mas converter, reproduzir, multiplicar. Não há necropolítica que se sustente hoje sem a voz tentadora de uma fantasma, sem a promessa de uma vida de poder que escala ossadas humanas em direção ao absoluto. Levar em consideração a questão do desejo é algo que se justifica, em última instância, pelo fato de que, sem ele, não há força que sustente essa série infinita de guerras, sem previsão de vitória definitiva, que faz vítimas de maneira indiscriminada - ainda que a distribuição de morte seja significativamente assimétrica. E, se lembrarmos que a necropolítica opera pela naturalização de uma forma de circulação de morte, distanciando a sociedade de uma perturbação generalizada diante da violência do necropoder, ficamos com o problema adicional que é: como interromper algo que é natural e cotidiano para nós? Algo que, talvez, tenha sido a única experiência íntima e constante para uma grande parcela da humanidade, e que, para o resto, é perfeitamente conciliável com a vida cotidiana. Se, novamente, queremos saber do que nos permitirá fechar o poço inesgotável de fantasmas e fantasias aberto na colônia, a destituição de certa organização do desejo e da fantasia aparece como condição de interrupção do circuito infernal da necropolítica - condição para que "emancipação" não se torne o nome de algo nunca acabado por ser sempre adiado por mais uma rodada contrarrevolucionária, enquanto crânios de parentes acumulam.

\section{IV}

Por fim, o último item da distinção entre o poder de matar e o necropoder: a multiplicação dos sentidos de "morrer" e "morte". Quando focamos demais nas práticas de assassinato direto ou indireto, acabamos deixando de lado uma das características fundamentais da necropolítica: ela produz uma realidade - os "mundos de morte". Não um fragmento de realidade, mas uma experiência terrivelmente abrangente, espaço-temporalidade em que "vida e morte se entrelaçam ao ponto de não sabermos mais distingui-los" (MBEMBE, 2001, p. 197, tradução do autor). O necropoder integra dimensões variadas da vida em sociedade no espetáculo pretensamente único e exclusivo do terror, o que significa submeter 
cada uma delas a uma experiência da morte como algo fora de onde devia estar. A colonização foi um trabalho massivo, em escala metafísica, de reunir o que estava separado e separar o que estava reunido, e um dos efeitos disso foi a invasão da vida pela morte como possibilidade de vida. Morrer em vida não é um processo de transformação no sentido de deixar de ser uma pessoa no caminho para se tornar outra - é algo que diz respeito à organização do social. Como nota Inaê Diana Ashokasundari Shravya da Costa Rossi (2020, p. 87):

Quando digo que já estamos mortos, estou me referindo às posições sociais que ocupamos. O regime neoliberal é ele mesmo um cadáver em putrefação. Como não o superamos, estamos nos revirando em suas vísceras. Daí temos posições sociais tentando se revitalizar, em vez de reconhecerem sua cadaveridade.

Trata-se da morte do corpo enquanto parte de uma ontologia social, e não mera organização somática, de modo que é apenas relativamente a essa construção da realidade que essas corpos podem ou não assumir sua própria morte ou tentar se revitalizar sem destruir a posição que ocupam. Se, na visão fanoniana, "a violência atuava como um instrumento de ressurreição" (MBEMBE, 2020, p. 129), isso significava uma forma de abolição que visava destituir as condições de cadaveridade e morte social. Essa destituição só é possível a partir do momento que o sujeito político reaparece na recusa a ser "reduzido a um monte de carne, a morrer de uma morte indesejada" (MBEMBE, 2018, p. 238). Essa morte é aquela que não tem qualquer motivo para ocorrer e pode acontecer a qualquer momento, não por azar, mas pela convergência de formas de matar em um espaço enclausurado, policiado, separado do resto, governado pela lógica da guerra sem lei. É a morte que acontece a familiares, pessoas conhecidas e distantes, aproximadas pelo medo daquilo que pode ou não acontecer, dependendo exclusivamente do exercício arbitrário da soberania, forma extrema de insegurança que torna a morte como possibilidade omnipresente: não se sabe quando e onde ela aparecerá, ainda que ela venha a todo momento e em todos os cantos no interior das fronteiras, ou mesmo além delas, como punição por uma transgressão imaginada.

Vive-se a morte, antes de tudo, como a única coisa a ser vivida, a única coisa a ocupar o horizonte de expectativas e com a qual se deve sempre estar em relação. Em casos extremos, pode-se "perceber que, de fato, nada mais há para se viver - que, no fundo, a morte se apresenta idêntica à vida" (MBEMBE, 2001, p. 198, tradução do autor). Como se percebe algo assim? A necropolítica sempre foi a tentativa de esvaziamento - a produção de vazios onde não se deseja ver certos poderes que diferenciam o humano de uma coisa inanimada qualquer. Sua eficácia reside na organização da subjetividade, forma de fazer parecer, para quem vive na morte, que houve efetivamente uma perda definitiva. Isso não significa a demanda por um resgate da realidade por trás das aparências, mas pela reorganização delas, pela reconstrução da percepção de si de modo a fazer aparecer o que havia saído do campo perceptivo, o que se encontra em um canto pouco iluminado, ou o que já não se encontra mais por estar soterrado de outras coisas. Assim, é preciso reencontrar cada uma das possibilidades que supostamente se perderam nas variadas formas de morrer, trabalho que vai dos músculos à dimensão existencial, da intimidade à socialidade. Em escala ainda maior, trabalho de restauração ou criação de laços, restituir a "possibilidade de um encontro genuíno com outros seres humanos" (MBEMBE, 2020, p. 18).

E, dada a impossibilidade da eliminação completa da humanidade pelo necropoder, é preciso trabalhar a distância entre o que se foi, o que é feito pela desumanização e o que se deseja ser, ainda que 
esse desejo não esteja previamente enclausurado em um projeto. E é inevitável operar nessa distância, no interior da própria morte social, onde os próprios recursos da vida serão encontrados. Da mesma forma que a violência é veneno e cura, o poder, para Mbembe, também passa por uma apropriação no sentido de que reencontramos, em nossa intimidade, aquilo que parecia apenas nos violentar de fora:

Não é possível circunscrever o poder aos limites de uma forma única estável, pois é de sua natureza participar do excedente. Todo poder, por princípio, só é poder por suas capacidades de metamorfose. Hoje leão, amanhã búfalo ou javali, no dia seguinte elefante, pantera, leopardo ou tartaruga [...] Ter poder é, portanto, saber dar e receber formas. (MBEMBE, 2018, p. 232-3)

Essas capacidades são experimentadas na própria plasticidade do sujeito: se ele pode ser destruído e reorganizado de fora, isso significa uma possibilidade que está ali e que pode se manifestar de outras maneiras. Parte da escrita de Mbembe se destina a nos lembrar e mostrar que, quando o próprio espaço é organizado pelo necropoder, o terreno por onde o sujeito se move, inclusive politicamente, é o da própria ruína. São inúmeras imagens que circulam pela obra de Mbembe que nos incitam a visualizar o que pode ser uma vida que se reergue quando a experiência cotidiana é marcada por uma série de ausências: de sentido, de estabilidade, de referência, de completude, de ordem, de linearidade, de paz, de coerência, de futuro distinto do passado e de vida sem a morte como assombração constante. Em todas essas ausências, a vida tende a se tornar permanentemente fragmentária e espectral, traumática e amaldiçoada. Mbembe escolhe nos apresentar o que significa a experiência vivida do necropoder dessa forma, e podemos considerar que se trata de uma maneira de nos levar a uma reavaliação de nossos desejos de segurança e perfeccionismos morais e políticos, além de um lembrete do que há em nós apesar e por causa de tudo - momento de reflexividade existencial da reorganização do olhar que é posta em movimento pelo trabalho conceitual em torno da necropolítica. "A metamorfose só é possível porque a pessoa humana jamais se remete a si mesma sem se referir a outra força qualquer, a um outro si-mesmo - a capacidade de sair de si, de duplicação e de estranheza, antes de mais nada em relação a si mesmo" (MBEMBE, 2018, p. 234).

\section{REFERÊNCIAS}

BUTLER, Judith. Senses of the subject. New York: Fordham University Press, 2015.

DA COSTA ROSSI, Inaê Diana Ashokasundari Shravya. "Diegese de gênero: esboço de uma crítica à metafísica sexual.". In: GALDINO, Victor; MEDEIROS, Claudio (Orgs.). Experimentos de filosofia pós-colonial. São Paulo: Editora Filosófica Politeia, 2020, pp. 75-97.

FANON, Frantz. Damnés de la Terre. Préface de Jean-Paul Sartre (1961); Préface d'Alice Cherki et postface de Mohammed Harbi (2002). Paris: Éditions La Découverte/Poche, 2002.

FERREIRA DA SILVA, Denise. "O evento racial ou aquilo que acontece sem o tempo (2016)". Em Adriano Pedrosa et al. (orgs.) Histórias afro-atlânticas vol. 2. São Paulo, MASP, 2018.

FOUCAULT, Michel. "Qu'est-ce que les Lumières?”. In: Dits et Écrits 1954-1988, Tome IV: 1980-1988. Édition établie sous la direction de Daniel Defert et François Ewald avec la collaboration de Jacques Lagrange. Paris: Éditions Gallimard, 1994, pp. 562-578. 
KILOMBA, Grada. Memórias da plantação: Episódios de racismo cotidiano. Tradução Jess Oliveira. Rio de Janeiro: Cobogó, 2019.

MBEMBE, Achille. "Achille Mbembe in conversation with Isabel Hofmeyr. In: South African Historical Journal, 56:1, p. 177-187, 2006.

Crítica da Razão Negra. Tradução de Sebastião Nascimento. São Paulo: n-1 edições, 2018.

. De la Postcolonie: Essai sur l'imagination politique dans l'Afrique contemporaine. Paris: Éditions Karthala, 2000.

. "De la Scène Coloniale chez Frantz Fanon". In: Rue Descartes, nº 58, 2007/4, p. 37-55.

. "Necropolítica". Arte \& Ensaios, PPGAV, EBA, UFRJ, n.32, dez. 2016.

. On the Postcolony. Berkeley: University of California Press, 2001.

. Políticas da inimizade. Tradução de Sebastião Nascimento. São Paulo: n-1 edições, 2020.

. Sair da grande noite: Ensaio sobre a África descolonizada. Tradução de Fábio Ribeiro. Petrópolis: Editora Vozes, 2019.

MCCLINTOCK, Anne. Couro imperial: Raça, gênero, e sexualidade no embate colonial. Tradução de Plinio Dentzien. Campinas: Editora da Unicamp, 2010.

RANCIÈRE, Jacques. A Partilha do Sensível. Tradução de Mônica Neto. São Paulo: Editora 34, 2009.

WILDERSON, Frank B. Afropessimism. New York: Liveright Publishing Corporation 2020. 
